\title{
Foveal thickness after phacoemulsification as measured by optical coherence tomography
}

\author{
Gerasimos Th Georgopoulos \\ Dimitrios Papaconstantinou \\ Maria Niskopoulou \\ Marilita Moschos \\ Ilias Georgalas \\ Chrysanthi Koutsandrea
}

Glaucoma Department, Medical School, Athens University, Athens, Greece
Correspondence: Gerasimos Th

Georgopoulos

Glaucoma Department,

Medical School, Athens

University, I I Likavitou Str,

10672 Athens, Greece

$\mathrm{Tel}+302 \mathrm{I} 03631658$

Email eyenet@hellasnet.gr
Background: Despite a significant body of research, no consistency on postoperative foveal thickness as measured by optical coherence tomography (OCT), can be recorded. The purpose of our study was to evaluate the effect of uncomplicated cataract surgery in the thickness of the retina in the foveal area during the early postoperative period.

Methods: In a prospective study, 79 eyes were assessed by OCT, on day 1, and weeks 2 and 4 after uncomplicated phacoemulsification with intraocular lens implantation in the Athens University Clinic. The outcome measure was the thickness of the retina in the foveal area.

Results: The thickness of the retina preoperatively is significantly smaller $(150.4 \pm 18.8)$ $(\mathrm{p}<0.05)$ than the thickness of the retina on day $1(171.8 \pm 21)$ and week $2(159.7 \pm 19)$ and returned to the initial levels on week $4(152 \pm 17.1)$. The estimated correlation coefficients between preoperative and postoperative thickness of the retina were significant $(\mathrm{p}<0.05)$. Conversely, no association was found between postoperative visual acuity and thickness of the retina, neither between the phacoemulsification energy and retinal thickness. Operation time, although inversely related with postoperative visual acuity, was not associated with the thickness of the retina.

Conclusions: Following phacoemulsification, an increase in the foveal thickness was detected in the early postoperative period, quantified and followed up by OCT. The foveal thickness returned to the preoperative level, 1 month following surgery in our study. No association was shown between intraoperative parameters and increased postoperative retinal thickness.

Keywords: optical coherence tomography, phacoemulsification, retinal thickness

\section{Introduction}

Postoperative cystoid macular edema (CME) is a well established complication of routine phacoemulsification or extracapsular cataract extraction and intraocular lens (IOL) implantation. Large studies report an incidence of visual loss from CME of 0.4\%-2\% (Kraff et al 1984; Norregaard et al 1999). In CME, visual acuity is inversely related to the foveal thickness (Nussenblatt et al 1987); subclinical CME appears in about $20 \%$ of the patients and can be detected by fluorescein angiography (Wright et al 1988; Ursell et al 1999).

Increased foveal thickness following cataract extraction and IOL has also, been associated with decreased visual acuity, measured 1 week postoperatively by optical coherence tomography (OCT) (Sourdille and Santiago 1999; Cheng et al 2002). OCT is a fairly new technique for high-resolution cross-sectional imaging of the retina which can quantify the development and resolution of foveal and extrafoveal macular thickening (Hee et al 1998).

Based on previous research (Degenring et al 2007; Biro et al 2008), it was hypothesized that the foveal thickness would be increased postoperatively. In line, pre- and postoperative foveal thicknesses associations were examined for the first time. The foveal thickness proportionality could thus be supported and potential measurement errors in pseudophakia could be excluded. 
The second hypothesis of our study was based on Cheng and colleagues (2002) findings that the best corrected visual acuity inversely relates to foveal thickness in the early postoperative period. Finally, a rarely addressed hypothesis, examined the relation between the amount of phacoemulsification energy and the foveal thickness; a similar hypothesis has been addressed only in one study that found proportionality between higher phacoemulsification power and increased mean foveal thickness (Cheng et al 2002). The operation time relation with foveal thickening and visual acuity was also examined.

The purpose of the current study was to examine the effect of uncomplicated phacoemulsification with IOL implantation to the central foveal thickness by OCT during a 4-week postoperative period, in eyes without CME.

\section{Materials and methods}

Between July and October 2006, 80 eyes of 80 consecutive patients scheduled for routine phacoemulsification and IOL implantation were included in this prospective study. Informed consent was obtained from all patients prior to their inclusion in the study. Twenty-seven males and 53 females were assigned. The mean age of our group was $\mathrm{M}=72.47$ $(\mathrm{SD} \pm 9.71)$ years.

All cataracts permitted a fairly detailed fundus examination. Exclusion criteria included any ocular diseases that might influence macular thickness such as history of uveitis, diabetes, age-related macular degeneration, intraoperative complications, and inferior quality measurements of OCT due to media opacities, as well as history of cataract surgery in the fellow eye within the previous 6 months. Since the study explored subclinical changes in the foveal thickness, 1 patient that developed clinical CME that was confirmed by OCT was excluded. Hence, 79 patients remained in the study.

All eyes received a complete ophthalmologic examination 1 day preoperatively that included best corrected visual acuity (BCVA), Amsler chart, slit lamp examination, IOP measurement, and dilated fundus examination. BCVA was recorded on Snellen chart in each visit. OCT (Stratus OCT3, Carl Zeiss Ophthalmic Systems) measurements were taken by an experienced operator, through a dilated pupil, at the same visit and at day 1, 2 weeks, and 1 month postoperatively. Past medical history was recorded.

During OCT examinations, six radial-line scans, $6,00 \mathrm{~mm}$ each in length, centered on the foveola were performed and a topographical map of the macula was produced. The minimum-central foveal value (CFV) was measured. The fellow eyes of the patients served as controls.
All cataract surgeries were performed by the same surgeon under topical anesthesia with a standard technique of clear corneal incision, capsulorhexis with forceps under a viscoelastic material and implantation of PC-IOL. All viscoelastic was carefully removed at the end. Antibiotic and steroid eye drops were given postoperatively for 3 weeks.

Pearson correlation coefficients were calculated to reveal potential significances amongst i) pre- and postoperative foveal thicknesses, ii) visual acuity and foveal thickness in the early postoperative period, iii) the operation time with foveal thickening as well as with visual acuity, and iv) phacoemulsification energy with foveal thickness.

Paired T-tests were computed to compare i) the BCVA before the operation and at day 1 post operatively and ii) the central foveal thickness (CFV) preoperatively and at day 1 , week 2 , and 1 month following the cataract extraction and the IOL implantation. Level of significance was set at 0.05.

\section{Results}

Descriptive statistics are depicted in Table 1.

Results were derived from paired t-tests for mean differences; preliminary analysis (Kolmogorov-Smirnov test) indicated that the data distribution is approximately normal. Fourteen percent of the data were missing. Missing value analysis in SPSS (SPSS Inc., Chicago, IL) indicated that the missing pattern was completely at random. For this reason, the statistical analysis was carried out with the available data only.

Regarding our first hypothesis, paired T-Tests (Table 2), compared CFV preoperatively and on post operative

Table I Descriptive statistics and values of main parameters

\begin{tabular}{ll}
\hline Group & $\mathrm{N}=79$ \\
Male & $\mathrm{N}=27$ \\
Female & $\mathrm{N}=52$ \\
Mean age & 72.47 \\
Visual acuity & Mean \pm SD \\
$\quad$ Preoperatively & $0.36 \pm 0.15$ \\
$\quad$ I day & $0.68 \pm 0.25$ \\
Central foveal value & Mean \pm SD \\
Preoperatively & $150.4 \pm I 8.84$ \\
$\quad$ I day & $171.82 \pm 21.10$ \\
$\quad 2$ weeks & $159.70 \pm 18.99$ \\
$\quad$ 4 weeks & $152.00 \pm 17.11$ \\
Phacoemulsification energy & Mean \pm SD \\
& $29.22(S D+46.21 /-29.22)$ \\
\hline
\end{tabular}


Table 2 Comparison of central foveal values pre- and postoperatively (T-Tests)

\begin{tabular}{lll}
\hline Preoperative foveal thickness & Postoperative I day & $\mathrm{P}=0.00$ \\
& Postoperative 2 weeks & $\mathrm{P}=0.008$ \\
& Postoperative 4 weeks & $\mathrm{P}=0.22$ \\
Postoperative I day & Postoperative 2 weeks & $\mathrm{P}=0.29$ \\
& Postoperative 4 weeks & $\mathrm{P}=0.21$ \\
Postoperative 2 weeks & Postoperative 4 weeks & $\mathrm{P}=0.18$ \\
\hline
\end{tabular}

day 1 , week 2 , and week 4 revealing increases for day 1 and week 2 ( $p$ values $<0.05$ ) but no differences for week 4 . In line, the estimated correlation coefficients between the preoperative and the 1-day $(r=0.87, p=0.000), 2$-week $(r=0.37$, $\mathrm{p}=0.004)$ and 4 -week $(\mathrm{r}=0.27, \mathrm{p}=0.033)$ postoperative CFV were significant (Table 3 ).

The BCVA was improved on day 1 of the postoperative period $(p=0.00)$. The $r$ coefficient between the preoperative visual acuity and the visual acuity on day 1 postoperatively was insignificant.

The anticipated phacoemulsification energy and operation time correlation with postoperative CFV was not significant.

\section{Discussion}

Optical coherence tomography (OCT) is a noncontact, noninvasive technique that allows frequent measurements of the retinal thickness and is well tolerated by the patients. It has a high degree of reproducibility and repeatability (Hee et al 1995; Koozekanani et al 2000; Massin et al 2001) and can demonstrate cystic changes. In contrast to fluorescein angiography, it quantifies retinal thickness in patients with $\mathrm{CME}$ (Hee et al 1995; Koozekanani et al 2000; Massin et al 2001).
In terms of our first hypothesis, the OCT detected increased CFV postoperatively on day 1 and week 2 , and this returned to preoperative levels in week 4 (Table 2). We postulate that phacoemulsification even when uncomplicated, may have an impact on the healthy retina; this could be attributed to factors such as the intraoperative photostress due to the microscope light or the intraoperative changes of the intraocular pressure caused by surge; this impact may be expressed as temporary thickening of the central retina, without causing any permanent retinal damage or affecting visual acuity.

Biro and colleagues (2008) found no differences between the preoperative and postoperative day 1 foveal and perifoveal retinal thickness. However, increases were found in the perifoveal 3.0 and $6.0 \mathrm{~mm}$ diameter and foveal area thickness on postoperative days 7, 30, and 60 (Degenring et al 2007). No significant differences in foveal thicknesses were detected in other studies in week 1 (Cheng et al 2002; Degenring et al 2007). Cheng and colleagues (2002) observed no increases in mean foveal thickness in week 1 in 80 patients. Degenring and colleagues (2007), showed no increase in minimal foveal thickness in postoperative day 1 and week 1 in the nondiabetic subgroup. Four weeks after surgery though, a significant increase in mean foveal thickness was detected.

Explaining this result variability between different studies is a challenging task, and no relevant attempts have been recorded. The mediation of confounders (eg, age, sex, race, body mass, axial length, or refractive state) (Koozekanani et al 2000; Massin et al 2001) is suggested to be controlled on the effect of cataract extraction and IOL implantation on foveal thickness.

Ching and colleagues (2006), in great contradiction to the aforementioned studies (Cheng et al 2002; Degenring et al 2007; Biro et al 2008), showed thicker preoperative foveal

Table 3 Correlation matrix (foveal thickness, visual acuity)

\begin{tabular}{|c|c|c|c|c|c|c|}
\hline & $\begin{array}{l}\text { Foveal thickness } \\
\text { Preoperative }\end{array}$ & $\begin{array}{l}\text { Foveal thickness } \\
\text { I day }\end{array}$ & $\begin{array}{l}\text { Foveal thickness } \\
2 \text { weeks }\end{array}$ & $\begin{array}{l}\text { Foveal thickness } \\
4 \text { weeks }\end{array}$ & $\begin{array}{l}\text { Visual acuity } \\
\text { preoperative }\end{array}$ & $\begin{array}{l}\text { Visual acuity } \\
\text { I day }\end{array}$ \\
\hline $\begin{array}{l}\text { Foveal thickness } \\
\text { preoperative }\end{array}$ & - & & & & & \\
\hline $\begin{array}{l}\text { Foveal thickness } \\
\text { I day }\end{array}$ & $0.870(p=0)$ & - & & & & \\
\hline $\begin{array}{l}\text { Foveal thickness } \\
2 \text { weeks }\end{array}$ & $0.367(p=0.004)$ & $0.298(p=0.020)$ & - & & & \\
\hline $\begin{array}{l}\text { Foveal thickness } \\
4 \text { weeks }\end{array}$ & $0.274(p=0.033)$ & $0.178(p=0.172)$ & $0.973(p=0)$ & - & & \\
\hline $\begin{array}{l}\text { Visual acuity } \\
\text { preoperative }\end{array}$ & $0.075(p=0.558)$ & $0.059(p=0.650)$ & $-0.032(p=0.82)$ & $-0.039(p=0.79)$ & - & \\
\hline $\begin{array}{l}\text { Visual acuity } \\
\text { I day }\end{array}$ & $0.167(p=0.265)$ & $0.273(p=0.060)$ & $0.134(p=0.433)$ & $0.142(p=0.414)$ & $0.65(p=0)$ & - \\
\hline
\end{tabular}


and central retinal thickness than those in the postoperative period, except when comparing the preoperative with the postoperative 4-week central thickness. The authors suggested their findings may be due to possible errors in preoperative measurements resulted from cataract or from an apparent thinning of the retina following the replacement of the lens, concluding that an adjustment in retinal thickness measures by the OCT is required following the cataract extraction. According to our results, however, such an adjustment is not indicated for the pseudophakic status, since significant correlations were found between preoperative and all postoperative foveal thicknesses (Table 3).

Sourdille and Santiago (1999), as well as Cheng and colleagues (2002) found that the BCVA inversely relates to the foveal thickness in the early postoperative period; in our study, no significant correlation coefficient was detected between visual acuity and foveal thickness in postoperative day 1 .

Regarding the hypothesized relation between the amount of phacoemulsification energy and the foveal thickness, no significant correlation was detected. According to a Chinese study (Cheng et al 2002), however, higher phacoemulsification power groups detect increased $(p<0.05)$ mean foveal thickness compared to lower phacoemulsification power groups in week 1 .

In conclusion, although visual acuity improves postoperatively, OCT recording reveals a significant increase in retinal thickness of the fovea on day 1 and week 2 that returned to the initial levels by the 1 st postoperative month in our sample. No correlation was found between phacoemulsification power and minimal foveal thickness or between visual acuity and foveal thickness in the early postoperative period. However, a possible limitation of the present study is the fact that very dense cataracts demanding a great amount of phacoemulsification energy or complicated cases were not evaluated.

\section{Acknowledgments}

The authors would like to thank Dr Efthimios Motakis, Genome Institute of Singapore, postdoctoral fellow for his statistical consultation and assistance. The authors report no conflicts of interest in this work.

\section{References}

Biro Z, Balla Z, Kovacs B. 2008. Change of foveal and perifoveal thickness measured by OCT after phacoemulsification and IOL implantation. Eye, 22:8-12.

Cheng B, Liu Y, Liu X, et al. 2002. [Macular image changes of optical coherence tomography after phacoemulsification]. Zhonghua Yan Ke Za Zhi, 38:265-7.

Ching HY, Wong AC, Wong CC, et al. 2006. Cystoid macular oedema and changes in retinal thickness after phacoemulsification with optical coherence tomography. Eye, 20:297-303.

Degenring RF, Vey S, Kamppeter B, et al. 2007. Effect of uncomplicated phacoemulsification on the central retina in diabetic and non-diabetic subjects. Graefes Arch Clin Exp Ophthalmol, 245:18-23.

Hee MR, Puliafito CA, Duker JS, et al. 1998. Topography of diabetic macular edema with optical coherence tomography. Ophthalmology, 105:360-70.

Hee MR, Puliafito CA, Wong C, et al. 1995. Quantitative assessment of macular edema with optical coherence tomography. Arch Ophthalmol, 113:1019-29.

Koozekanani D, Roberts C, Katz SE, et al. 2000. Intersession repeatability of macular thickness measurements with the Humphrey OCT 2000. Invest Ophthalmol Vis Sci, 41:1486-91.

Kraff MC, Sanders DR, Jampol LM, et al. 1984. Effect of primary capsulotomy with extracapsular surgery on the incidence of pseudophakic cystoid macular edema. Am J Ophthalmol, 98:166-70.

Massin P, Vicaut E, Haouchine B, et al. 2001. Reproducibility of retinal mapping using optical coherence tomography. Arch Ophthalmol, 119:1135-42.

Norregaard JC, Bernth-Petersen P, Bellan L, et al. 1999. Intraoperative clinical practice and risk of early complications after cataract extraction in the United States, Canada, Denmark, and Spain. Ophthalmology, 106:42-8.

Nussenblatt RB, Kaufman SC, Palestine AG, et al. 1987. Macular thickening and visual acuity. Measurement in patients with cystoid macular edema. Ophthalmology, 94:1134-9.

Sourdille P, Santiago PY. 1999. Optical coherence tomography of macular thickness after cataract surgery. J Cataract Refract Surg, 25:256-61.

Ursell PG, Spalton DJ, Whitcup SM, et al. 1999. Cystoid macular edema after phacoemulsification: relationship to blood-aqueous barrier damage and visual acuity. $J$ Cataract Refract Surg, 25:1492-7.

Wright PL, Wilkinson CP, et al. 1988. Angiographic cystoid macular edema after posterior chamber lens implantation. Arch Ophthalmol, 106:740-4. 